\title{
Conscientização e participação: as relações públicas comunitárias na construção da cidadania
}

Awareness and participation: the community
public relations in the development of citizenship

Concientización y participación: las relaciones públicas comunitarias en la construcción de la ciudadanía

Marcelo Pereira da Silva

- Pós-doutorando em Comunicação pela Universidade Estadual Paulista (Unesp) - Bauru

- Doutor em Comunicação Social pela Universidade Metodista de São Paulo (Umesp)

- Mestre em Comunicação Midiática pela Unesp - Bauru

- Professor do curso de Relações Públicas da Universidade Federal do Maranhão (UFMA)

- E-mail: marcelosilva_rp@hotmail.com

\section{Ellida Neiva Guedes}

- Doutora em Ciências da Comunicação pela Universidade de Coimbra (UC)

- Mestre em Ciências da Comunicação pela Escola de Comunicações e Artes da Universidade de São Paulo (ECA-USP)

- $\quad$ Professora de Relações Públicas na Universidade Federal do Maranhão (UFMA)

- E-mail: ellidaguedes@gmail.com

- Doutor em Desenvolvimento Sustentável do Trópico Úmido pela Universidade Federal do Pará (UFPA)

- Mestre em Comunicação pela Universidade Federal do Rio de Janeiro (UFRJ)

- Professor do Curso de Relações Públicas na Universidade Federal do Maranhão (UFMA)

- E-mail: labcom17@bol.com.br 


\section{Resumo}

Os processos que constituem a sociedade e as organizações carecem da ativa participação dos sujeitos na transformação da realidade, considerando a necessidade de uma consciência sensível às demandas sociais e que produzam modos de pensar que levem à ação. Este artigo discute, por meio de pesquisa bibliográfica, a formação da consciência do sujeito e os desafios das relações públicas comunitárias no fomento da participação dos atores sociais para a construção da cidadania, vislumbrando uma sociedade mais igualitária e solidária.

PALAVRAS-CHAVE: RELAÇÕES PÚBLICAS COMUNITÁRIAS • CONSCIÊNCIA • PARTICIPAÇÃO • CIDADANIA • TRANSFORMAÇÃO.

\section{Abstract}

The processes that establish the society and the organizations need the active participation of the subjects to change the reality, pursuant to the need for consciousness sensitive to the social demands and generating ways of thinking that lead to action. This article discusses, using bibliographic research, the development of the subject's awareness and the challenges of community public relations in fostering the participation of social players in the construction of citizenship, foreseeing a more equitable and solidary society.

\section{KEYWORDS: COMMUNITY PUBLIC RELATIONS •AWARENESS • PARTICIPATION •CITIZENSHIP・CHANGE.}

\section{Resumen}

Los procesos que constituyen la sociedade y las organizaciones carecen de la participación activa de los sujetos en la transformación de la realidad, considerando la necesidad de una consciencia sensible a las demandas sociales y que produzcan modos de pensar que llevan a la acción. Este artículo problematiza, a través de investigación bibliográfica, la formación de la consciencia del sujeto y los desafíos de las relaciones públicas comunitarias en el fomento de la participación de los actores sociales para la construcción de la ciudadanía, vislumbrando una sociedade más igualitaria y solidaria. 
$\mathrm{N}$ a sociedade contemporânea observa-se, amiúde, a discussão sobre a necessidade de os atores sociais participarem dos processos que a constituem, de modo presencial, em grupos organizados ou por meio das redes sociais digitais, bem como a ampliação de oportunidades para efetivar essa participação. Os conceitos de participação (Freire, 1979) trazem elementos e valores comuns, que vêm ao encontro dos interesses deste artigo, já que se associam à construção da cidadania: exercício de direitos e cumprimento de deveres, emancipação, desenvolvimento social, respeito à pluralidade e às diferenças, prática de relações democráticas e norteadas pela tolerância.

Etimologicamente, entende-se o termo cidadão como o habitante da cidade, aquele detentor do direito à vida, liberdade, propriedade e igualdade perante a lei. É o indivíduo que deve desenvolver habilidade de consciência de seus direitos e deveres, participando, ativamente, das questões ligadas à sociedade e à sua comunidade. A efetivação da participação não ocorre na solidão do sujeito, mas à medida que ele se faz comunicante (Freire, 1971).

Desse modo, a cidadania implica o direito do homem de reconhecer-se pertencente a uma comunidade/sociedade, integrante do patrimônio comum e, ainda, partícipe do processo de construção do desenvolvimento social. A prática da cidadania leva os atores sociais ao sentimento de pertencimento, à constituição da identidade, à ação política consciente e ao exercício pleno de direitos e deveres. Compreende-se a cidadania como o direito pleno à vida quando aquele "habitante da cidade" assume as questões políticas, sociais, culturais e jurídicas como luta pessoal e coletiva.

Em Durkheim (1995) se tem a explicação do "haver", "existir" e "fazer" a ligação entre os homens, a qual, maior ou menor, mecânica ou orgânica, leva a um "prender-se" uns aos outros, isto é, à solidariedade. É pelo desenvolvimento e pela maturidade da consciência individual e coletiva que se dá o processo de solidariedade social, que vem a formar ou realçar os valores e os sentimentos comuns entre as pessoas e que estão presentes na construção/prática da cidadania.

O desafio do homem está em educar/transformar/(re)construir a sociedade de modo a garantir o pleno exercício da condição de cidadão e a análise crítica da realidade no lugar de ator social, ou seja, de protagonista. Um dos meios para vencer esse desafio é a formação de uma consciência para a participação política, que pode se dar pela educação e pela comunicação. É nesse campo que atuam as relações públicas comunitárias, incentivando a participação dos sujeitos nos processos sociais e a prática da problematização das realidades, em busca de desenvolvimento social, contribuindo para o (re)conhecimento do direito (e do dever) de cada um assumir-se como protagonista de sua própria história.

Entretanto, o protagonismo e a prática cidadã, em meio à pobreza e às desigualdades sociais crescentes, ficam comprometidos, o que afasta o "habitante da cidade" da esfera política e abre possibilidades para a manipulação política e a alienação social daquele que deveria participar da construção de sua existência.

Considerando-se tal cenário, este artigo objetiva discutir a atuação das relações públicas comunitárias nos processos de conscientização e participação dos atores sociais na construção da cidadania, a partir dos conceitos de consciência e participação políticas. Coloca-se na ribalta a função social desse campo da comunicação na promoção da transformação social, através da mediação entre Estado, sociedade e mercado.

\section{CONSCIÊNCIA, PARTICIPAÇÃO E CIDADANIA: DIALOGANDO CONCEITOS}

A consciência, para Abbagnano (2003, p. 185), é "uma relação da alma consigo mesma, uma relação intrínseca ao homem, interior ou 'espiritual', pela qual ele pode conhecer-se de modo imediato e privilegiado". Está associada à inteligência que 
faz um juízo a respeito do certo e do errado para a própria pessoa, de um ato já praticado ou a praticar. A consciência é, portanto, pessoal, individual e irrepetível, pois representa a convicção interna na decisão moral aqui e agora, orientando 0 autoconhecimento e o comportamento humanos.

Comportamento, na perspectiva daética, implica a tomadadedecisões(entre obeme omal) ea assunção de responsabilidades, nos planos individual e coletivo, o que determina a consciência e a liberdade como faces da mesma moeda. Somente ao ato humano consciente e livre se pode atribuir uma responsabilidade.

Para Cotrim (1999, p. 44), a "consciência é estar no mundo com algum saber, 'com-ciência'", o que remete à capacidade do homem de debruçar-se "sobre si mesmo para tomar posse de seu próprio saber". A tomada de consciência do eu e do mundo, que faz com que o homem se descubra como uma estrutura dinâmica, dota-o da capacidade de análise e o leva à reflexão, em um processo contínuo e aberto para um relacionamento consigo mesmo e com o mundo. Nesse sentido, a consciência mobiliza a inteligência do sujeito para que possa enfrentar a complexidade do existir e da vida.

O homem, do ponto de vista da biologia, é classificado como sapiens, o ser que sabe que sabe - logo, dotado de consciência -, o que o distingue dos animais, já que eles não sabem que sabem. 0 ser humano é (ou deveria ser) capaz de dominar a realidade em que vive, a leitura e o estar no mundo, de construir conhecimentos que the permitam viver e estabelecer com o universo uma relação indispensável, em busca de encontrar respostas para suas inquietações e necessidades, (re) conhecendo a sua própria existência. Vê-se, nesse trabalho, o homem em uma perspectiva mais ampla que a biológica, posto que é, para Morin (2012, p. 140), "sapiens e demens, afetivo e lúdico, imaginário, poético, prosaico".

Cada ser humano constitui uma unidade essencial e suas atitudes são avaliadas a partir de si mesmo, uma vez que a consciência é sempre consciência de algum valor enleado à realidade do sujeito. Assim, acredita-se que, pela consciência, o homem emerge da biosfera para iniciar a formação do seu mundo específico, a noosfera - coisas do espírito, saberes, ideias, mitos, crenças, etc. (Morin, 2012).

A consciência torna-se o resultado de um processo de interação entre indivíduo e sociedade, mas, também, fruto da educação. Não é, portanto, patrimônio hereditário, já que resulta de um longo e complexo processo. A educação tem como fim primário a formação do indivíduo, qualificando-o para a sua ação. Logo, a falta do saber "gera a dependência, a submissão e subserviência" (Luckesi; Passos,1992, p. 42).

Assim, a formação da consciência resulta do processo interativo natural do homem como ser social. Ao mesmo tempo, dele exige-se "ter consciência" para estar no mundo e se relacionar com o outro, decidindo entre o certo e o errado, o bem e o mal. A consciência é indispensável para o exercício da cidadania, esta um modo de viver igual e justo para todos os indivíduos. Observase a dimensão política do conceito de consciência e, a partir dela, um caminho para a construção e o exercício da cidadania.

A palavra política vem do grego pólis, que significa cidade. Política é uma atividade coletiva que visa chegar à maneira mais adequada de compor os interesses e as necessidades de todos em torno de um denominador comum. A prática da cidadania e a formação para tal ocorrem nesse contexto. Onde falta consciência política, sobressai o Estado prepotente e avassalador, o político corrupto e um Estado paternalista que assiste ao cidadão achando que faz "favores", embora o faça com o dinheiro dos impostos pagos pela sociedade. 0 não-exercício da consciência política também pode facilitar o não-cumprimento dos deveres e das responsabilidades de empresas públicas, privadas ou do terceiro setor com os grupos de pessoas afetados por elas - funcionários, comunidades, cidadãos e consumidores. 
A consciência política exige conhecimento, capacidade de questionar e analisar e, sobretudo, relacionamento com 0 mundo político (poderes, processos e instituições). Somente assim, o homem, em uma dinâmica contínua de educação, estará apto a reconhecer a capacidade de governos e instituições de assegurar a felicidade coletiva e a exercer seus direitos e deveres na transformação social necessária.

Com base no entendimento do que significa a consciência política, compreende-se que a cidadania se constrói na interação entre os sujeitos e deles com outras forças constitutivas da sociedade. A cidadania "se expressa nas dimensões civil, social e política e se concretiza na liberdade de opinião e expressão, de participação política e no acesso aos bens necessários à vida e ao desenvolvimento intelectual" (Peruzzo, 2007, p. 46). Segundo a autora, o desenvolvimento de uma sociedade pode ser medido de acordo com o maior ou menor grau de exercício dos direitos e deveres dos cidadãos, pressupondo a participação ativa da população local, a sustentabilidade, a corresponsabilidade do cidadão e de suas organizações, mercado, empresas e Estado, respeito aos valores dos envolvidos e retorno a eles na forma de benefícios.

Ser partícipe do processo de construção social legitima o homem como cidadão, sendo os principais pilares para o exercício cidadão a participação e o protagonismo na construção social. Para Teixeira (2001), há várias formas de participação, das quais depreendem-se elementos e valores comuns como solidariedade, despreocupação com a tomada de poder, respeito à pluralidade e às diferenças e prática de relações democráticas. Participação pressupõe uma relação em que os atores, com os recursos disponíveis, "fazem valer seus interesses, aspirações e valores, construindo suas identidades, afirmando-se como sujeitos de direitos e obrigações" (Teixeira, 2001, p. 26). Para Freire (1981, p. 18-19), o sujeito deve ter um compromisso com o mundo, cuja existência não se resume à articulação retórica, mas apenas com "engajamento com a realidade".

No campo da política, a participação, segundo o autor, ocorre em uma interação entre o Estado, outras instituições políticas (partidos, grupos de pressão) e a própria sociedade, em um processo que articula os interesses privados para influenciar as decisões do Estado.

No Brasil, o agravamento dos conflitos sociais, a desigualdade entre as classes econômicas, o deficitário quadro educacional, de saúde, segurança e moradia, aliados à crescente conscientização de vários segmentos sociais, até mesmo por causa do ambiente das tecnologias de informação e comunicação, promoveram o surgimento de modos de participação diversos, outros formatos de relacionamentos pessoais, institucionais e políticos, novas formas de organização de interesses. $A$ isso Teixeira (2001) chama de nova cultura política, em que se valorizam a ação coletiva, a construção de identidades, a criação e efetivação de direitos e o enfrentamento dos problemas sociais.

De acordo com a World Values Survey (WVS), pesquisa realizada pela Universidade de Michigan, em cerca de oitenta países, com perguntas sobre valores socioculturais, morais, religiosos e políticos dos países pesquisados, e aplicada no Brasil entre 1995 e 2005, o aumento da participação do brasileiro foi significante em instituições pertencentes tanto à sociedade política, quanto à sociedade civil. Tal participação ocorre, principalmente, através de instituições desvinculadas da sociedade política, e suas ações políticas buscam mecanismos não ligados ao aparato estatal (Castro; Reis, 2012).

Por outro lado, a crescente desigualdade entre ricos e pobres, a corrupção que domina o ambiente político e a consequente descrença da sociedade nesse sistema, e a busca desenfreada pelo sustento diário, que esgota todo o tempo dos cidadãos, dificultam e até impedem a participação consciente e livre dos atores sociais, nas questões que dizem respeito à sua existência. 
Participar, em termos políticos, envolve ações não necessária nem exclusivamente ligadas ao ato de votar nas eleições, apontando para os contextos institucionais do Estado ou iniciativas informais, por exemplo. Para Avelar (2007), as atividades imbricadas na participação política podem ser as mais simples, como conversas com amigos sobre os acontecimentos políticos locais, nacionais e internacionais, até as mais complexas, como fazer parte de governos, mobilizar pessoas para protestar contra autoridades políticas, associar-se em grupos e movimentos para reivindicar direitos, envolver-se nas atividades da política eleitoral, votar, candidatar-se, pressionar autoridades para mudanças nas regras constitucionais para favorecer grupos de interesses dos mais diversos etc.

A participação política pode se caracterizar por ações coletivas ou individuais, apoiando ou pressionando, com o objetivo de influenciar as tomadas de decisão que envolvam interesses coletivos, nos campos político, social ou comunitário. Trata-se de um processo que pode tornar os cidadãos melhores e mais fortes, à medida que promove a reflexão, exige argumentação, consolida a solidariedade, já que se orienta pelo compartilhamento de interesses e anseios. Nesse sentido, Bauman (2017, p. 24) assevera que a humanidade está em crise e que "não existe outra saída para ela senão a solidariedade dos seres humanos", indicando que os obstáculos no caminho são: a recusa ao diálogo, a insensibilidade e o desprezo ao outro.

Pode-se dizer, então, que os direitos e deveres constituídos expressam os princípios básicos da cidadania - igualdade e liberdade - e são indicadores do grau de desenvolvimento social de um país ou uma região, em uma perspectiva igualitária, permanente e duradoura. A maior ou menor organicidade dos cidadãos fortalece ou enfraquece uma sociedade e está diretamente relacionada à consciência política e à capacidade de articulação dos atores sociais, em cada período histórico. Desse modo, concebe-se consciência política como um dos caminhos do processo de conquista e prática da cidadania.

A construção da cidadania implica participação, no sentido de interferir, decidir, modificar, criar e usufruir, igualmente, de direitos e deveres. Nesse universo, o propósito das relações públicas comunitárias, através de uma comunicação participativa, é mobilizar os atores envolvidos para a participação social e política, o que pode conduzi-los para a problematização e transformação de suas realidades, de modo consciente, no exercício do papel de protagonistas de sua própria história.

É no conceito de homem transformador do mundo, no âmbito da educação libertadora de Freire (1979), que as ações de relações públicas comunitárias se sustentam. Assim, a área revela "sua função social de práxis voltada para a transformação social, no estabelecimento da integração entre Estado, sociedade e mercado" (Oliveira, 2007, p. 181), em direção a uma sociedade mais justa, com políticas públicas e de comunicação participativa definidas para o exercício da cidadania, 0 respeito às individualidades e o desenvolvimento social sustentável.

\section{AS RELAÇÕES PÚBLICAS COMUNITÁRIAS NO PROCESSO DE CONSTRUÇÃO DA CIDADANIA}

A dimensão comunitária das relações públicas nasceu no cenário social brasileiro dos anos 1980', marcado por pressões populares em torno do direito à cidadania e convulsionado por greves, ocupações de terras, protestos contra o alto custo de

\footnotetext{
1 Waldemar Luiz Kunsch (2007, p. 107-123) considera como marco do que viriam a ser as relações públicas comunitárias o IX Congresso Anual da União Cristã Brasileira de Comunicação Social (UCBC), em 1980. Esse evento teve um painel sobre relações públicas a serviço dos interesses da comunidade e dos movimentos sociais organizados, no qual sobressaíram José J. Queiroz, Cicília M. Krohling Peruzzo e Margarida M. Krohling Kunsch. 0 autor destaca o papel desempenhado nesse contexto pela PósGraduação em Comunicação Social do então Instituto Metodista de Ensino Superior, que em sua primeira fase (1979-1985), segundo Marques de Melo (1983, p. 194) tinha "uma preocupação científica com os fenômenos não-hegemônicos ou contra-hegemônicos da comunicação nas sociedades dependentes", especialmente porque a Metodista se localiza no ABC Paulista, onde surgiram diversas experiências populares de comunicação. A partir do evento da UCBC, Cicília e Margarida publicaram uma série de textos que estão na origem do desenvolvimento dessa perspectiva das relações públicas comunitárias.
} 
vida, ação pastoral engajada na formação política e surgimento de movimentos populares, indicativos de um processo de mudança social. Surgiam meios alternativos de comunicação, mas faltava explicitação teórica da viabilidade de as relações públicas servirem aos interesses populares (Peruzzo, 2009).

As relações públicas comunitárias viabilizam-se pela comunicação comunitária, cuja origem remonta à ação dos movimentos sociais populares típicos do final dos anos 1970 e se fundamenta na democracia, na representatividade, no caráter coletivo e no protagonismo do cidadão, desde o planejamento até a gestão dos processos de interesses coletivos.

A organização e o crescimento dos movimentos sociais ocorreu em decorrência do deficitário contexto brasileiro no atendimento aos direitos dos cidadãos nos campos educacional, habitacional e de saúde. A busca pela diminuição de tais deficiências passou a fazer parte do enfrentamento e da luta pela democratização de direitos, através de uma práxis coletiva capaz de interferir nas estruturas e políticas públicas, orientada pela comunicação comunitária, articulando 0 primeiro, segundo e terceiro setores da sociedade.

A comunicação comunitária, portanto, está

vinculada às lutas mais amplas de segmentos empobrecidos da população, mas organizados, e tem a finalidade de contribuir para solucionar problemas que afetam o dia a dia das pessoas e a ampliar os direitos de cidadania (...) porque contribui para gerar conhecimento e para mudar as condições concretas de existência (Peruzzo, 2008, p. 2).

As mudanças e melhorias na vida das pessoas podem decorrer dos processos de mobilização e conscientização implantados e implementados pela comunicação comunitária, que favorecem o exercício da cidadania, à medida que oportunizam a participação do cidadão no processo comunicativo e na luta em busca do atendimento de suas demandas, na conquista e ampliação de direitos. A comunicação comunitária torna-se um mecanismo de luta e de legitimação dos direitos de cidadania, contribuindo para a formação de cidadãos capazes de compreender o mundo e de se organizarem para transformá-lo, através de ações concretas, com vistas a melhorar a consciência política e a sensibilidade acerca de causas sociais.

Como se sabe, o homem constrói sua consciência nas interações que estabelece em diferentes mediações sociais, culturais e educativas e com outras forças constitutivas da sociedade, condição necessária para ele estar no mundo, relacionar-se com o outro e ser capaz de distinguir e decidir entre o certo e o errado. Daí ser a consciência indispensável para a participação ativa do homem em suas realidades, no sentido de nelas pensar, interferir e decidir, modificando-as para a construção de uma cidadania plena. Por seu caráter educativo, a comunicação comunitária tem grande relevância nesse processo.

Nesse contexto, as relações públicas comunitárias implementam o tripé conscientização-mobilização-ação², buscando despertar nos cidadãos as capacidades de compreensão e intervenção na realidade e incentivando a participação política da população para a criação e adoção de políticas comunicativas e sociais adequadas.

As relações públicas, na dimensão comunitária, fazem a mediação entre movimentos organizados, órgãos públicos e empresas privadas (Kunsch, 2007), buscando atender às demandas das classes populares ou de segmentos com interesses específicos, em um cenário complexo e deficitário nos planos social, educacional, habitacional, ambiental, de saúde etc. $\mathrm{A}$ função mediadora vai além do processo de informar, alcançando o intercâmbio de informações, a geração de conhecimento, o diálogo e a construção de relacionamentos, com vistas a despertar a participação dos cidadãos, tornando-os gestores da construção da cidadania. 0 caráter mediador promove, ainda, a compreensão e a problematização da realidade social.

2 Além de um movimento de conscientização, acredita-se na urgência de um processo de sensibilização, já que o processo de "dar consciência" ao sujeito é desafiado pela vontade de consciência por parte desse sujeito; conscientizar deixa entrever um sujeito passivo, "dominado" pelo conscientizador. 
Nesse sentido, Kunsch (2007) destaca que são amplas as frentes de trabalho para as relações públicas comunitárias, tanto nas instituições do terceiro setor, como no âmbito do Estado, onde ações comunicativas proativas e empreendedoras podem ser realizadas em prol do desenvolvimento integral da sociedade. No segundo setor, considerando-se a relevância do público comunitário, as organizações têm adotado práticas de responsabilidade social para melhorar a qualidade de vidas das pessoas e contribuir para a diminuição das desigualdades sociais.

As ações nesses campos tornam-se possíveis por meio de uma comunicação fiel a valores como igualdade, fraternidade, liberdade e solidariedade, os quais compõem o "panteão do pensamento democrático" (Wolton, 2006, p.11), que persegue há mais de um século o desejo incessante de ampliar o horizonte do mundo, das relações e da produção da justiça social.

As relações públicas comunitárias podem ser desenvolvidas nos planos empresarial, governamental e de instituições sem fins lucrativos, desde que se constituam de modo participativo e democrático, a partir das demandas dos públicos envolvidos, priorizando seu protagonismo, do planejamento à gestão dos processos de interesses coletivos, com o objetivo de promover a emancipação humana. A natureza dessa comunicação tipifica o cuidado com o outro, zelando por um diálogo que seja libertador, sinérgico e construtor de uma "aliança perene de paz e amortização" (Boff, 2008, p. 139).

A comunicação comunitária representa, nesse universo, uma esperança para a diminuição da desigualdade e da injustiça sociais, bem como para a constituição/formação de sujeitos-protagonistas, desenvolvendo ações comunicativas e uma forma de pensar que os coloque no centro da cena, como pensadores, propositores e promotores de mudanças, agentes conscientes da transformação.

0 modo como hoje a sociedade se organiza, gerando um tipo de ativismo contemporâneo, com renovados formatos de organização, táticas, métodos e estratégias, evidencia a relevância da comunicação. As muitas lutas por direitos de toda ordem a que se assiste e a pluralidades de vozes em busca de um espaço no qual possa ecoar a quantidade de informações nos muitos meios disponíveis levam a desafios como os apontados por Henriques (2007, p. 100): "1. Apresentar e defender publicamente seus interesses (relacionamento público); 2. Lidar com uma variedade de públicos em busca da legitimação de sua existência e adesão às suas causas; 3. Manter os vínculos horizontais entre os atores envolvidos".

Observa-se que as relações públicas comunitárias têm a função de promover a coesão interna dos movimentos, pelo diálogo, incentivando a participação ao ampliar e diversificar os interlocutores e "os conteúdos sintonizados com questões cotidianas, temas dos âmbitos legislativo e judiciário, difusão de descobertas científicas e tecnológicas, alternativas de geração de rend" (Peruzzo, 2013, p. 56), em direção ao desenvolvimento integral dos indivíduos.

Tais desafios, diz Henriques (2007), requerem a definição de estratégias de mobilização, com a criação de condições de ação em rede entre os atores mobilizados, em uma acepção política de defesa pública de interesses por meio do relacionamento entre instituições e públicos. Nessa dinâmica, o empoderamento de processos comunicacionais autônomos tem sido percebido como necessidade na condição de canais de expressão concernente à mobilização e organização populares. Cremades (2009, p. 24) defende que, apenas "quando uma pessoa é consciente da capacidade de influência e ação que lhe permite se integrar com outras pessoas, surge o micropoder", ou seja, o protagonismo do sujeito na comunicação comunitária exige a conjugação de autonomia e integração.

Os desafios também estão na conquista da visibilidade da causa, do movimento e de seu posicionamento público, como portadores de legitimidade. Evidencia-se que, em última instância, o objetivo das estratégias é a transformação de uma dada 
realidade social, por meio da "restruturação da difusão do poder, engendrada pela participação cidadã, pelo acesso à informação e a necessidade imperiosa de uma democracia como "diálogo social" (Cremades, 2009, p. 25). A esse respeito, Castells (2013, p. 21) afirma que, "para que as redes de contrapoder prevaleçam sobre as redes de poder embutidas na organização da sociedade, elas têm de reprogramar a organização política, a economia, a cultura ou qualquer dimensão que pretendam mudar".

O desenvolvimento das relações públicas comunitárias profissionaliza um processo de comunicação mobilizadora, já que ele ocorre naturalmente, a todo o momento, em todos os lugares, de muitas formas, com objetivos distintos e formas diversificadas, oportunizando à área o exercício de uma práxis social na gestão organizacional no primeiro, segundo ou terceiro setor, em consonância com as experiências dos atores envolvidos no processo. Todos se tornam responsáveis pela crítica, problematização e (re)construção da realidade, na perspectiva da construção da cidadania.

A ascensão do terceiro setor tem proporcionado oportunidades e levantado desafios para a comunicação. A possibilidade de sensibilizar e conscientizar os sujeitos para a relevância de seu engajamento em questões ligadas à realidade de sua comunidade, escola, universidade, cidade, estado, país etc. produz uma socialidade capaz de influenciar e cooperar na construção de sociedades mais justas e solidárias, em um mundo permeado pela lógica do individualismo egoísta.

Os sujeitos estão imersos em uma realidade norteada pela perversidade do sistema capitalista concorrencial de consumo, o qual gera uma volta ao canibalismo. Em virtude das dificuldades para "um convívio social saudável e para o exercício da democracia" (Santos, 2013, p. 54), em seu sentido mais amplo, a comunicação comunitária emerge como uma esperança para fazer frente à cultura consumista.

Essecenário reverbera na forma como os sujeitos vivem e caminham na esfera do consumo, cimentando a urgente necessidade da comunicação comunitária não apenas como contraposição ao espírito desse tempo, mas como uma esperança ao que se vê proliferar em forma de individualismo, dilacerando a realidade e as relações sociais.

\section{CONSIDERAÇÕES FINAIS}

O surgimento e a prática da dimensão comunitária das relações públicas disponibilizam o conhecimento construído nesse campo para a luta por uma sociedade mais justa, de modo alinhado aos saberes populares e, principalmente, incentivando 0 protagonismo dos atores sociais na discussão, proposição, transformação e no desenvolvimento social (Freire, 1971, 1979, 1981).

Como destaca Kunsch (2007), o princípio orientador do processo da comunicação comunitária é o conceito de educação libertadora de Paulo Freire (1979), que concebe o homem como transformador do mundo. Tal transformação, entretanto, tem um caráter coletivo, pois se inicia na relação entre os homens - é na interação que os homens se educam, se conscientizam e se libertam da omissão, opressão e dependência, emancipando-se.

O propósito comunicativo das relações públicas comunitárias de promover a conscientização, no âmbito da libertação, visa despertar o homem para a descoberta dele como sujeito de si e do mundo em que vive, preparando-o/estimulando-o para a formação da consciência necessária para o conhecimento e a problematização da realidade, que conduz a respostas sobre o mundo, e para os relacionamentos sociais e políticos. Também lança luz sobre as mudanças no ambiente comunicacional, as quais afetam "as normas de construção de significado" e a "produção de relações de poder" (Castells, 2013, p. 11). 
Em tal processo, o viés educativo das relações públicas comunitárias revela-se na formação e conscientização do indivíduo para a prática da cidadania, que o impulsiona para a ação em direção às mudanças necessárias para um desenvolvimento social participativo, democrático e sustentável.

A comunicação comunitária possibilita aos atores sociais a produção de conhecimento sobre o mundo e, a partir dele, competências para transformá-lo - portanto, gera consciência, poder, sensibilidade e capacidade de influenciar e tomar decisões. Por outro lado, a falta de consciência política abre espaço para a dependência ideológica, já que o homem fica destituído da capacidade de distinguir e decidir, não assumindo responsabilidades, e para a atuação de instituições e grupos descomprometidos com as causas sociais coletivas.

A responsabilidade social das relações públicas evidencia-se na construção da cidadania, desmistificando o caráter predominantemente capitalista que permeia as ações da área no terreno empresarial. Amplia-se, assim, o âmbito de sua atuação em uma sociedade cada vez mais plural, caleidoscópica e complexa.

As relações simétricas propostas pelas relações públicas comunitárias atam-se, umbilicalmente, à ordem dos valores e significam que o respeito ao outro e a confiança são irmãos gêmeos. Comunicar acontece "entre", ou seja, exige reconhecer-se o outro como sujeito e ter por ele alguma estima. Esse cuidado torna-se parte essencial da identidade de organizações e movimentos comunitários: o outro não apenas passa a ter voz e ação, mas a existir, tecer e transformar sua história, individual e coletivamente.

A comunicação não promove, ipso facto, a compreensão humana, porque ela necessita de uma disposição subjetiva. Todavia, a comunicação comunitária pode reduzir as incompreensões que reinam nas relações sociais. A luta constante é o preço que se tem que pagar por um mundo menor e mais próximo, recortado por técnicas refinadas, interativas e personalizadas, mas, ainda, distante do ideal de um mundo mais justo e habitável para todos. Na coxia de Freire, asseveramos que a realidade apenas pode ser transformada quando o homem descobre que é ela modificável e que ele é sujeito dessa mudança (Freire, 1981).

A comunicação comunitária descobre a alteridade radical e o dever da construção de um mundo melhor no qual todos os indivíduos são valorizados, predominando a sensibilidade e o respeito no lugar da hostilidade, do desprezo e do ódio. A equalização das questões-problema e das aporias da sociedade hodierna passam, fundamentalmente, pelo coração humano. A falta de amor obnubila as virtudes da alteridade: a perspectiva comunitária as traz para o centro do palco.

\section{REFERÊNCIAS}

ABBAGNANO, Nicola. Dicionário de filosofia. 4. ed. São Paulo: Martins Fontes, 2003.

AVELAR, Lúcia. Participação Política. In: AVELAR, Lúcia; CINTRA, Antônio Octávio (Orgs.). O sistema político brasileiro: uma introdução. Rio de Janeiro: Fundação Konrad Adenauer, 2007. p. 261-280.

BAUMAN, Zygmunt. Estranhos à nossa porta. Rio de Janeiro: Zahar, 2017.

BOFF, Leonardo. Saber cuidar. ética do humano - compaixão pela terra. 15. ed. Petrópolis, RJ: Vozes, 2008.

CASTELLS, Manuel. Redes de indignação e esperança: movimentos sociais na era da internet. Rio de Janeiro: Zahar, 2013. 
CASTRO, HenriqueC. deOliveira de; REIS, FernandaTeixeira. Participação política no Brasilno séculoXXI: mudanças econtinuidades. Revista de Ciência Política, v. 21, n. 2, p. 20-33, jul./dez. 2012. Disponível em: <http://dx.doi.org/10.4322/tp.2012.015>.

COTRIM, Gilberto. Fundamentos da filosofia: ser, saber e fazer. 14. ed. São Paulo: Saraiva, 1999.

CREMADES, Javier. Micropoder. a força do cidadão na era digital. São Paulo: Senac, 2009.

DURKHEIM, Émile. Divisão do trabalho social. São Paulo: Martins Fontes,1995.

FREIRE, Paulo. Conscientização. São Paulo: Moraes Editora, 1971.

Pedagogia do oprimido. 7. ed. Rio de Janeiro: Paz e Terra, 1979.

Educação e mudança. Rio de Janeiro: Paz e Terra, 1981.

HENRIQUES, Márcio Simeone. Ativismo, movimentos sociais e relações públicas. In:KUNSCH, Margarida M. Krohling;KUNSCH, Waldemar Luiz (Orgs.). Relações públicas comunitárias: a comunicação numa perspectiva dialógica e transformadora. São Paulo: Summus, 2007. p. 92-104.

KUNSCH, Margarida M. Krohling. Dimensões e perspectivas das relações públicas comunitárias. In: KUNSCH, Margarida Maria Krohling; KUNSCH, Waldemar Luiz (Orgs.). Relações públicas comunitárias: a comunicação numa perspectiva dialógica e transformadora. São Paulo: Summus, 2007. P.165-180.

KUNSCH, Margarida Maria Krohling; KUNSCH, Waldemar Luiz (Orgs.). Relações públicas comunitárias: a comunicação numa perspectiva dialógica e transformadora. São Paulo: Summus, 2007.

KUNSCH, Waldemar Luiz. Resgate histórico das relações públicas comunitárias no Brasil. In: KUNSCH, Margarida Maria Krohling; KUNSCH, Waldemar Luiz (Orgs.). Relações públicas comunitárias: a comunicação numa perspectiva dialógica e transformadora. São Paulo: Summus, 2007. p. 107-123.

LUCKESI, Carlos Cipriano; PASSOS, Elizete Silva. Introdução à filosofia. Salvador: Centro Editorial e Didático da UFBA, 1992.

MARQUES DE MELO, José. Da comunicação popular à popularização da ciência. Comunicação \& Sociedade, São Bernardo do Campo, PósCom-IMS, n. 9, p. 193-205, 1. sem. 1983.

MORIN, Edgar. O método - 5. A humanidade da humanidade: a identidade humana. Porto Alegre: Sulina, 2012.

OLIVEIRA, Maria José da Costa. Relações públicas e as questões sociais nos três setores da sociedade. In: KUNSCH, Margarida M. Krohling; KUNSCH, Waldemar Luiz (Orgs.). Relações públicas comunitárias: a comunicação numa perspectiva dialógica e transformadora. São Paulo: Summus, 2007. p.181-193.

PERUZZO, Cicília M. Krohling. Cidadania, comunicação e desenvolvimento social. In: KUNSCH, Margarida Maria Krohling; KUNSCH, Waldemar Luiz (Orgs.). Relações públicas comunitárias: a comunicação numa perspectiva dialógica e transformadora. São Paulo: Summus, 2007. p. 45-58. 
Conceitos de comunicação popular, alternativa e comunitária revisitados e as reelaborações no setor. Palabra Clave - Revista da Facultad de Comunicación, Universidad de la Sabana ,Cundinamarca/Colombia, v. 11, n. 2, p. 367 379, dez. 2008. Disponível em: <http://palabraclave.unisabana.edu.co/index.php/palabraclave/article/ view/1503/1744>. Acesso em: 02 mar. 2016.

Da aparência à essência das relações públicas: abordagem na perspectiva da teoria crítica e do modo de produção capitalista. In: KUNSCH, Margarida M. Krohling (Org.). Relações públicas: história, teorias e estratégias nas organizações contemporâneas. São Paulo: Saraiva, 2009. p.157-184.

Comunicação nos movimentos sociais: o exercício de uma nova perspectiva de direitos humano. Contemporânea | comunicação e cultura, Poscom UFBA, v. 11, n. 1, p. 138-158, jan./abr. 2013. Disponível em: <http://www.portalseer.ufba.br/ index.php/ contemporaneaposcom/article/view/6980>. Acesso em: 3 abr. 2015.

SANTOS, Milton. Por uma outra globalização. 23. ed. Rio de Janeiro: Record, 2013.

TEIXEIRA, Elenaldo Celso. O local e o global: limites e desafios da participação cidadã. São Paulo: Cortez, 2001.

WOLTON, Dominique. É preciso salvar a comunicação. São Paulo: Paulus, 2006.

Texto recebido em 07.04.2017 e aprovado em 30.06.2017. 